\title{
Bronchiectasis: an orphan disease with a poorly-understood prognosis
}

\author{
T. Keistinen*, O. Säynäjäkangas*+, T. Tuuponen*, S-L. Kivelä*\#
}

Bronchiectasis: an orphan disease with a poorly-understood prognosis. T. Keistinen, $O$. Säynäjäkangas, T. Tuuponen, S-L. Kivelä. OERS Journals Ltd 1997.

ABSTRACT: The prognosis and risk factors for bronchiectasis are at present poorly known. The aim of this study was to examine the long-term prognosis and cause of death in this disease.

The National Hospital Discharge Register was used to search for patients aged 3574 yrs, with newly-diagnosed bronchiectasis in the period 1982-1986. Each of the 842 patients identified was matched with an asthmatic patient and a patient with chronic obstructive pulmonary disease (COPD), who were of the same age and sex and who had been treated in hospital at the same time. The use of hospital services by these subjects was examined up to the end of 1992, and mortality to the end of 1993 .

The prognosis for the bronchiectatic patients treated in hospital was better than that for the COPD patients but poorer than that for the asthmatics; the risk of death being 1.25 (95\% confidence interval (95\% CI) 1.15-1.36) for the COPD patients and $0.79(95 \%$ CI $0.71-0.87)$ for the asthmatics, relative to the bronchiectatic patients. Bronchiectasis was the main cause of death in $13 \%$ of bronchiectatic patients, the risk of death being increased by a factor of 1.21 in the presence of asthma as the main secondary diagnosis, by 1.31 with COPD, by 1.35 with tuberculosis and its sequelae, and by 1.32 with some other secondary diagnosis, as compared with cases for which no secondary diagnosis was indicated.

The fact that the prognosis for bronchiectatic patients is poorer than that for asthmatics points to a continued need for focused care and follow-up, particularly in the presence of additional illnesses.

Eur Respir J 1997; 10: 2784-2787.
*Dept of Public Health Science and General Practice, University of Oulu, Oulu, Finland. +Lapland Central Hospital, Dept of Pulmonary Diseases, Rovaniemi, Finland. \#Unit of General Practice, Oulu University Hospital, Oulu, Finland.

Correspondence: T. Keistinen

Aapistie 1

FIN-90220 Oulu

Finland

Keywords: Asthma

bronchiectasis

chronic obstructive pulmonary disease prognosis

Received: February 251997

Accepted after revision September 31997
Effective antimicrobial medication, the decline in the incidence of tuberculosis and the existence of effective vaccination schemes have improved the prognosis for bronchiectasis in recent decades [1-3]. According to a report published in 1940, most patients succumbed before the age of $40 \mathrm{yrs}$ [4], and even in the 1960s their average age at death was no more than 55 yrs [5]. The aim of the present investigation was to examine the long-term prognosis for patients with bronchiectasis and their causes of death on the basis of register data.

\section{Materials and methods}

The National Research and Development Centre for Welfare and Health maintains a register of all hospital treatment periods, including patients' social security numbers, dates of admission and discharge and treatment diagnoses. All treatment periods recorded for 1972-1992 with a principal diagnosis of bronchiectasis (rubrics 518, International Classification of Diseases (ICD) eighth revision, up to 1986, and 494, ICD ninth revision, from then onwards), asthma (493, ICD, eighth and ninth revisions) or chronic obstructive pulmonary disease (COPD) (491-492, ICD eighth revision, and 491, 492 and 496, ICD ninth revision) were collected from the register.
A patient with bronchiectasis was considered to be a new case if he or she had been treated in hospital for this disease on or after January 1, 1982, but not 1972-1981, and new asthmatics and COPD patients were defined in the same way. Data on all new patients aged 35-74 yrs treated for these diseases in 1982-1986 were collected from the register, comprising 842 with bronchiectasis, 15,208 with asthma, and 10,115 with COPD.

Each new bronchiectatic patient was matched with one new asthmatic and one new COPD patient of the same sex and with the same year of birth, who had been discharged from hospital as close as possible to the same date. The average discrepancy in discharge dates was 5.1 (SD 5.9) days for the control asthmatics and 26.0 (SD 48.9) days for the control COPD patients.

Secondary diagnoses were utilized by collecting all treatment periods recorded for new bronchiectatic patients between 1982 and 1986 in which bronchiectasis had been the main diagnosis and asthma (493), COPD (491 and 492, ICD eighth revision, and 491, 492 and 496, ICD ninth revision), tuberculosis and its sequelae (010-019, Y34.09, Y34.19 and Y34.29, ICD eighth revision, and 010-018 and 137, ICD ninth revision), or some other diagnosis code, had appeared as the main secondary diagnosis for the first time in 1982-1992. The effects of these secondary diag- 
noses on the prognosis for the new bronchiectatic patients could then be assessed.

From December 31, 1993, mortality data on all the new asthmatic, bronchiectatic and COPD patients aged 35-74 yrs, who had been treated in hospital in 1982-1986, were obtained from Statistics Finland. Kaplan-Meier survival analysis was then used to analyse the survival times, and the Cox regression procedure with time-constant covariates for the predictor variables in the cumulative survival function. The results were presented as risk ratios with $95 \%$ confidence intervals (95\% CIs). Statistical calculations were performed using the Statistical Package for the Social Sciences (SPSS) release 7.0 for Windows.

\section{Results}

\section{Mortality and survival}

The new bronchiectatic patients comprised 372 males, of average age 56 (SD 11) yrs and 470 females of average age 55 (SD 11) yrs. They had an average of 2.2 treatment periods (range 1-51) in 1982-1992, with bronchiectasis as the main diagnosis. There had been 239 deaths (28\%), $54 \%$ of them male, by the end of 1993, at which point the longest follow-up had lasted for 12.9 yrs. Correspondingly, 165 of the new asthmatics had died (20\%), $60 \%$ of them male, and 319 of the new COPD patients (38\%), of which $58 \%$ were male.

The prognosis for the bronchiectatic patients was poorer than that for the asthmatics but better than that for the COPD patients (fig. 1), the risk of death being 0.79 (95\% CI 0.71-0.87) for the former and 1.25 (95\% CI 1.15-1.36) for the latter, relative to that of the bronchiectatic patients. The outcome regarding the new bronchiectatic patients was that $25 \%$ of them died over a follow-up period of $8.8 \mathrm{yrs}, 25 \%$ of the males within $6.8 \mathrm{yrs}$ and $25 \%$ of the females within 10.7 yrs. In the case of the asthmatics, total mortality and female mortality had not reached 25\% within the follow-up period 1982-1993,

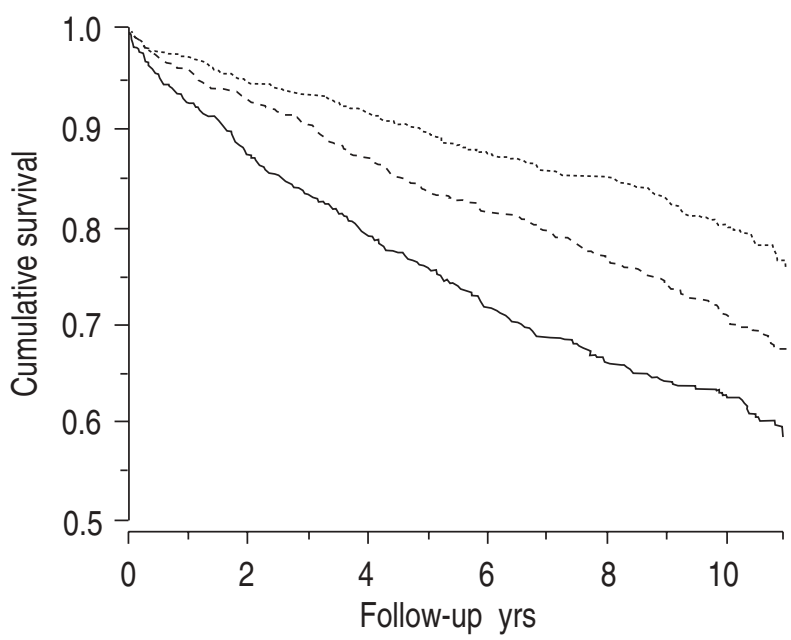

Fig. 1. - Survival of new asthma (........ ), bronchiectatic (.... $)$ and chronic obstructive pulmonary disease (— ) patients, aged 35-74 yrs treated in hospital in 1982- 1986. whereas $25 \%$ of the males had died within 9.0 yrs. By contrast, $25 \%$ of the COPD patients had died within 5.2 $\mathrm{yrs}$, the figures being $3.2 \mathrm{yrs}$ for the males and $8.4 \mathrm{yrs}$ for the females.

\section{Causes of death}

The primary disease was the cause of death for $13 \%$ of the bronchiectatic patients, whilst $22 \%$ of the deaths were of cardiac origin, $10 \%$ attributable to COPD, $5 \%$ to pneumonia, and $2 \%$ to asthma. The main cause of death among the asthmatics was cardiac disease (39\%), whereas the COPD patients had mostly died of their primary disease, (28\%). Pneumonia had been the cause of death for $3 \%$ of the former and $4 \%$ of the latter.

\section{Risk factors}

The risk of death was 1.28 times greater for the male bronchiectatic patients than for the females (95\% CI 1.131.46), and higher among more elderly cases, each year increasing the risk by $11 \%$ (95\% CI 9-12\%).

A secondary diagnosis was stated for half of the patients treated in hospital for bronchiectasis in 1982-1992, this being asthma in 39 cases (5\% of the total bronchiectasis group), COPD in 116 (14\%), tuberculosis and its sequelae in $46(6 \%)$, and some other diagnosis in 237 (28\%). Those without secondary diagnoses were found to survive better (fig. 2), whilst asthma as the main secondary diagnosis increased the risk of death by a factor of $1.21(95 \%$ CI $0.86-1.71)$ relative to the cases without a secondary diagnosis, COPD by 1.31 (95\% CI 1.08-1.58), tuberculosis and its sequelae by 1.35 (95\% CI 1.02-1.77), and some other secondary diagnosis by 1.32 (95\% CI 1.12-1.54).

Repeated treatment periods with bronchiectasis as the main diagnosis had no impact on the prognosis, each additional treatment period increasing the risk of death by $1.6 \%(95 \%$ CI $-1.4 \%$ to $+4.7 \%)$.

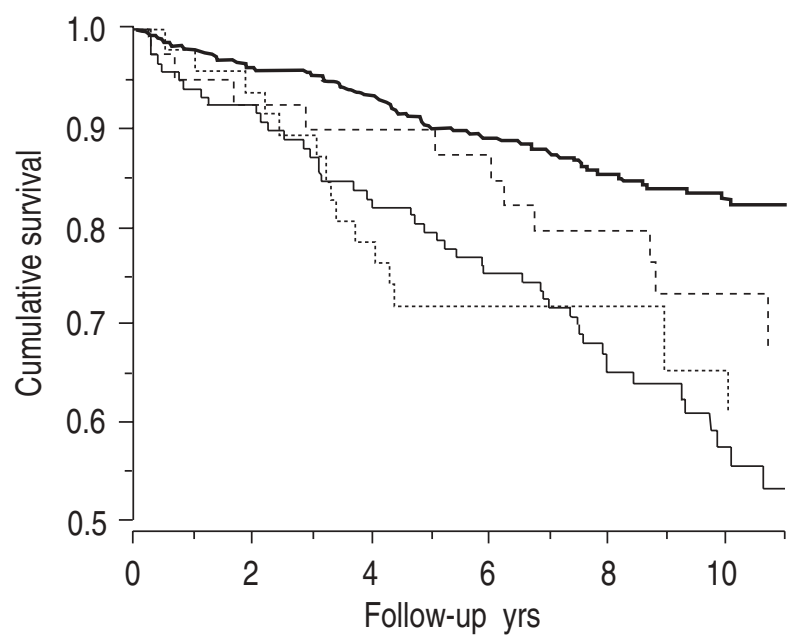

Fig. 2. - Effects of secondary diagnoses on the survival of new bronchiectatic patients, aged 35-74 yrs, treated in hospital in 19821986. — : no secondary diagnosis; ….... : asthma; - - - - : tuberculosis; $\quad$ : chronic obstructive pulmonary disease. 


\section{Discussion}

The principal findings reported here, that $25 \%$ of the bronchiectatic patients had died within 9 yrs $(13 \%$ of their primary disease), and that their survival was poorer than for the asthmatics, although better than that of the COPD patients, are in agreement with the observation that bronchiectasis was the primary cause of death for some $10 \%$ of patients with this disease in the 1970s and 1980s [6, 7], but deviate from the data published in the 1940s indicating that bronchiectasis was the primary cause of death in $78 \%$ of such patients who succumbed during the follow-up period [4]. It should be noted, however, that the investigations differ in terms of population and methods. Overall, the literature about the prognosis of bronchiectasis has been very limited, especially during the last $10 \mathrm{yrs}$.

The discharge register maintained by the National Research and Development Centre for Welfare and Health is an extensive one, covering all the hospitals in Finland, and the correspondence between its diagnosis data and patient records has been found to be good, as high as $95 \%$ [8]. Of the bronchiectasis diagnoses concerned here, $89 \%$ were verified in the units of pulmonary medicine, mostly by bronchography, which increases their reliability. Highresolution computed tomography (HRCT), now an excellent means of recognizing bronchiectasis, was introduced to Finland as late as 1989.

Chronic bronchitis clearly merges into bronchiectasis [7], and it is not easy to distinguish these two diseases. However, there was less of an overlap with bronchiectasis in the 842 COPD patients, as 3\% of these patients had bronchiectasis as a main diagnosis in 1972-1992. The accu- racy of the asthma and COPD diagnoses is improved by the fact that they are based on hospitalization periods with an average duration of 1 week. The same version of the disease classification was in use throughout the above period, which makes for greater consistency in diagnostic practices.

Autopsies were carried out on average in $20 \%$ of all dead persons in the whole population in Finland during the follow-up. The causes of death were judged according to the death certificates registered in Statistics Finland. It seems, on the basis of the death certificates, that asthmarelated mortality is underestimated [9] and that the reliability of the certificates with respect to asthma tends to decrease with the age of the patient [10]. On the other hand, actual asthma-related deaths in the register of causes of death can be taken to reflect the real situation, as the false-positive cases tend to compensate for false-negative ones [11]. COPD is evidently underrecorded as a cause of death [12], and the same is true of bronchiectasis.

Although the material used here is selective, as it ignores out-patient cases, it can be assumed to reflect the relationship between the prognoses for asthma, bronchiectasis and COPD correctly, as these diseases are all virtually equally severe when treated in hospital.

While bronchiectasis is characterized by an inflammatory "vicious circle" [13] which has to be managed by means of interventions, COPD can be regarded as a progressive disease resistant to treatment [14], and asthma as a progressive disease in which the advance can be slowed down by anti-inflammatory medication [15]. Total mortality among persons developing asthma at over $35 \mathrm{yrs}$ of age differs from that observed in the population as a whole only if some other pulmonary disease is also present [16]. The results obtained here can, thus, be considered consistent with the pathophysiology of these diseases and the treatment practices employed.

The fact that the prognosis for male bronchiectatic patients is worse than that for females may be attributable to the longer life expectancy of Finnish females and the higher prevalence of smoking among males. Repeated treatment periods have no effect on mortality, being in part rehabilitative and, thus, serving to improve the prognosis. This is also true of asthma [17].

Tuberculosis is an example of a necrotizing pneumonia with sequelae that may be extensive parenchymal destruction and fibrosis [1], leading to a restrictive ventilation deficit but also to chronic airways obstruction [18]. Obstructive pulmonary diseases impair clearance of the lungs $[19,20]$, and apparently to a higher degree if accompanied by bronchiectatic. The prognosis for bronchiectatic patients is impaired by the presence of diseases of the airways [7, 21], which is in agreement with the present findings.

The introduction of high-resolution computed tomography has improved the diagnosis of bronchiectasis, and emphasis should now be placed on the role of treatment and follow-up measures, and the influence of concomitant diseases, as the prognosis for these patients is poorer than that for asthmatics.

\section{References}

1. Barker AF, Bardana EJ Jr. Bronchiectasis: update of an orphan disease. Am Rev Respir Dis 1988; 137: 969-978.

2. Stockley RA. Bronchiectasis: a management problem? $\mathrm{Br}$ J Dis Chest 1988; 82: 209-219.

3. Trucksis M, Swartz MN. Bronchiectasis: a current view. Curr Clin Top Infect Dis 1991; 11: 170-205.

4. Perry KMA, King DS. Bronchiectasis: a study of prognosis based on a follow-up of 400 patients. Am Rev Tuberc 1940; 41: 531-548.

5. Konietzko NFJ, Carton RW, Leroy EP. Causes of death in patients with bronchiectasis. Am Rev Respir Dis 1969; 100: 852-858.

6. Sanderson JM, Kennedy MCS, Johnson MF, Manley DCE. Bronchiectasis: results of surgical and conservative management. A review of 393 cases. Thorax 1974; 29: 407-416.

7. Ellis DA, Thornley PE, Wightman AJ, Walker M, Chalmers J, Crofton JW. Present outlook in bronchiectasis: clinical and social study and review of factors influencing prognosis. Thorax 1981; 36: 659-664.

8. Keskimäki I, Aro S. Accuracy of data on diagnoses, procedures and accidents in the Finnish Hospital Discharge Register. Int J Health Sciences 1991; 2: 15-21.

9. Hunt LW Jr, Silverstein MD, Reed CE, O'Connell EJ, O Fallon WM, Yunginger JW. Accuracy of the death certificate in a population-based study of asthmatic patients. JAMA 1993; 269: 1947-1952.

10. Sears MR, Rea HH, de Boer G, et al. Accuracy of certification of deaths due to asthma: a national study. Am J Epidemiol 1986; 124: 1004-1011.

11. Wright SC, Evans AE, Sinnamon DG, MacMahon J. Asthma mortality and death certification in Northern Ireland. Thorax 1994; 49: 141-143.

12. Speitzer FE, Fay ME, Dockery DW, Ferris BG Jr. Chronic obstructive pulmonary disease mortality in six US cities. Am Rev Respir Dis 1989; 140: S49-S55. 
13. Cole PJ. Inflammation: a two-edged sword - the model of bronchiectasis. Eur J Respir Dis 1986; 69 (Suppl. 147): 6-15.

14. Burrows B, Bloom JW, Traver GA, Cline MG. The course and prognosis of different forms of chronic airways obstruction in a sample from the general population. N Engl J Med 1987; 317: 1309-1314.

15. Haahtela T, Järvinen M, Kava T, et al. Comparison of a $\beta_{2}$-agonist, terbutaline, with an inhaled corticosteroid, budesonide, in newly detected asthma. $N$ Engl $\mathrm{J}$ Med 1991; 325: 388-392.

16. Silverstein MD, Reed CE, O'Connell EJ, Melton LJ, O'Fallon WM, Yunginger JW. Long-term survival of a cohort of community residents with asthma. $N$ Engl $J$ Med 1994; 331: 1537-1541.

17. Ulrik CS, Frederiksen J. Mortality and markers of risk of asthma death among 1,075 out-patients with asthma. Chest 1995; 108: 10-15.

18. Snider GL, Doctor L, Demas TA, Shaw AR. Obstructive airway disease in patients with treated pulmonary tuberculosis. Am Rev Respir Dis 1971; 103: 625-640.

19. Goodman RM, Yergin BM, Landa JF, Golinvaux MH, Sackner MA. Relationship of smoking history and pulmonary function tests to tracheal mucous velocity in nonsmokers, young smokers, ex-smokers, and patients with chronic bronchitis. Am Rev Respir Dis 1978; 117: 205214.

20. Pavia D, Bateman JRM, Sheahan NF, Agnew JE, Clarke SW. Tracheobronchial mucociliary clearance in asthma: impairment during remission. Thorax 1985; 40: 171-175.

21. Ripe E. Bronchiectasis. I. A follow-up study after surgical treatment. Scand J Respir Dis 1971; 52: 96-112. 